\title{
ANÁLISE DE DEGRADAÇÃO DE SUPERFÍCIE DE LENTES DE CONTATO*
}

\section{Resumo}

Hugo de León Carvalho Cedro' José Luiz Paralovo²

Silvânia Alves de Carvalho José Augusto Oliveira Huguenin ${ }^{4}$ Elivelton Alves Ferreira ${ }^{5}$ Ingrid Russoni de Lima ${ }^{6}$ Ladário da Silva ${ }^{4}$

O presente trabalho tem como objetivo avaliar os efeitos da degradação da superfície de lentes de contato via métodos ópticos. Sendo biomateriais, as lentes estão em contato direto com estruturas sensíveis do corpo humano e seu uso surge da necessidade de reduzir enfermidades, propiciando melhora da acuidade visual e proteção ocular. Outro aspecto relevante é que as lentes se tornam uma nova estrutura refrativa de entrada da luz no globo ocular, e desse modo devem manter características de transmitância compatíveis com a córnea. Com o uso das lentes, é esperado uma degradação natural das propriedades ópticas e superficiais da mesma. Para avaliarmos essa degradação, foi planejado um experimento com um ensaio de degradação. O ensaio de degradação visa comparar o efeito de diferentes soluções simuladoras sobre a superfície das lentes tóricas: solução extrema de acetato de potássio 5\% pH5, solução fisiológica usada pelo fabricante do tipo Boston Simplus multiação e solução de água ultrapura obtida de um dispositivo milli-Q (controle). $O$ efeito da degradação foi analisado através do estudo das variações da topografia e da transmitância da lente.

Palavras-chave: Lentes de contato; Degradação; Topografia; Transmitância.

\section{Abstract}

\section{CONTACT LENS SURFACE DEGRADATION ANALYSIS}

The present work aims to evaluate the surface degradation of contact lenses by optical methods. As biomaterials, lenses have direct contact with sensible structures of human body and its use arises from the necessity to reduce infirmities, yielding improvement in the visual acuity and ocular protection. Another important point is that the lenses act as a new refractive structure and so they should maintain optical properties such as transmittance compatible with the cornea. As the lenses are used, a natural degradation of both optical and superficial properties is expected. In order to evaluate this degradation, an experiment was devised. The degradation essay intends to compare the effect of different solutions: $5 \% \mathrm{pH} 5$ potassium acetate, ultrapure milli- $Q$ water and Boston Simplus solution multiplier. The degradation effect was analyzed through topographic lenses surface variations and lens transmittance.

Keywords: Contact lenses; Degradation; Topography; Transmittance.

1 Enfermeiro, Mestrando em Engenharia Metalúrgica, Programa de Pós-Graduação em Engenharia Metalúrgica (PPGEM), Escola de Engenharia Industrial Metalúrgica de Volta Redonda (EEIMVR), Universidade Federal Fluminense (UFF), Volta Redonda, RJ - Brasil.

2 Químico, Instituto de Ciências Exatas (ICEX), UFF, Volta Redonda, RJ - Brasil

3 Física, Doutora em Física, Professora, Faculdade de Tecnologia, Universidade do Estado do Rio de Janeiro, Resende, RJ-Brasil

4 Físico, Doutor em Física, Professor, Departamento de Física, ICEx, UFF, Volta Redonda, RJ Brasil

5 Doutor em Química, Professor, Departamento de Química, Instituto, ICEx, UFF, Volta Redonda, RJ - Brasil

6 Dentista, Doutora em Patologia, Pós-Doutoranda - PNPD/CAPES, PPGEM, UFF, Volta Redonda, RJ - Brasil. 


\section{INTRODUÇÃO}

As lentes de contato, classificadas essencialmente como lentes gelatinosas [1] e rígidas [2], são materiais poliméricos que podem ser rígidos ou gelatinosos e possuem diversas aplicações médicas em oftalmologia, como as mais significativas pode-se citar: a correção visual de miopia, hipermetropia e astigmatismo, a transmissão de medicamentos para a superfície ocular, auxílio na manutenção da cicatrização epitelial e a proteção da córnea contra ressecamento [3]. Em 1936, foi fabricada nos Estados Unidos a primeira lente composta por polimetilmetacrilato transparente, considerada assim, a primeira lente de material polimérico. Até esse momento as lentes possuíam apoio escleral. Em 1947, K.Tuohy [4] desenvolveu a primeira lente com apoio corneal com diâmetros de 11 a $12,5 \mathrm{~mm}$ e espessura de $0,4 \mathrm{~mm}$, modelo aperfeiçoado em 1950 por G. Butterfield [4]. Em 1960, Otto Wichterle e Drahoslav Lim [5] especificaram as principais características que o material deveria possuir para ser adaptado ao olho humano, como por exemplo, retenção de conteúdo de água, material inerte a processos biológicos com resistência a degradação e permeabilidade aos metabólitos. Algumas enfermidades, e principalmente as incuráveis, possuem acentuada necessidade dessas características das lentes de contato devido à fragilidade da córnea. Dentre elas destaca-se o ceratocone [6]. Trata-se de uma doença degenerativa, não inflamatória, bilateral e assimétrica progressiva, que afeta a córnea transformando sua superfície na forma aproximada de um cone irregular. Seu tratamento paliativo mais eficaz é o uso lentes de contato para correção da ametropia. As lentes de contato possuem indicação médica para os casos de ceratocone, astigmatismo irregular, opacificação da córnea, afácia unilateral, anisometropia, nistagmo, após cirurgia refrativa, uso cosmético e uso terapêutico [7].

O objetivo da análise fotométrica é avaliar a transmitância da luz através das lentes de contato [8]. O microscópio confocal tem como objetivo a construção de imagens tridimensionais, através da leitura de uma sequência de cortes ópticos ou uma sequência de pontos em diferentes planos focais, funcionando também como um rugosímetro, é capaz de construir os perfis de rugosidade [9].

O ensaio de degradação [10] pode ser definido como o processo no qual uma reação química altera a qualidade de interesse de um material. Quando realizado de modo estático, visa analisar a capacidade das lentes de contato suportarem situações adversas.

\section{MATERIAIS E MÉTODOS 2.1 Materiais}

Para realização do estudo foram utilizadas as lentes de contato Bausch \& Lomb, modelo quantum I, diâmetro $9,20 \mathrm{~mm}$, com curva base variável de $33,00 \mathrm{D}$ a $55,00 \mathrm{D}$, a qual atende a graus esféricos de $-25,00 \mathrm{D} \mathrm{a}+25,00 \mathrm{D}$. Elas são utilizadas para correção de altas ametropias e apresentam alta transmissibilidade de oxigênio (Dk/t=92), o que permite o seu uso prolongado com descarte anual.

As soluções selecionadas para a pesquisa foram as de acetato de potássio (solução extrema, pH 5 em uma concentração de $0,1 \mathrm{~mol}$ de $\mathrm{HCl}$, a solução de buffer fisiológica proposta pelo fabricante do tipo Boston Simplus do tipo multiação e água ultrapura (controle), obtida de um dispositivo milli-Q. Para avaliar o efeito da degradação da superfície das lentes de contato via métodos ópticos, foram selecionados a análise superficial e óptica da lente. A análise superficial se baseou na variação temporal da topografia da superfície [1] da mesma obtida por microscopia confocal. A análise 
óptica usou a variação da transmitância [8] da lente de contato, obtida pelo modo fotométrico de um elipsômetro. Neste estudo as lentes foram numeradas da seguinte forma: lente 1 imersa na solução proposta pelo fabricante (Boston Simplus solução multiação), lente 2 imersa em acetato de potássio e lente 3 em água mili-Q.

Para a avaliação superficial das lentes de contato, usou-se um microscópio confocal interferométrico LEICA DCM3D (figura 1), que combina tecnologia confocal e interferometria para medições em alta velocidade e alta resolução (até $0,1 \mathrm{~nm}$ ). Ele fornece imagens confocais, que consistem na formação de imagens separadas para cada plano focal, e de campo claro simultaneamente e é possível construir imagens tridimensionais para análise da textura e topografia da superfície medida.

Para a medida de transmitância foi utilizado o elipsômetro espectrométrico, modelo GES 5S da SEMILAB. Trata-se de um elipsômetro com polarizador rotativo e lente de focalização (microspot). Sua fonte de luz é uma lâmpada de xenônio, com faixa útil de espectro de $200 \mathrm{~nm}$ a $1000 \mathrm{~nm}$. Ele pode ser utilizado no modo de fotometria para obtenção de transmitância e reflectância, ou no modo de elipsometria para obtenção de propriedades ópticas e dielétricas de variados materiais [11].

\subsection{Métodos}

As aquisições da topografia da superfície da lente de contato foram feitas no tempo 0 (controle) antes do ensaio de degradação, e usando as diferentes soluções de degradação para os tempos indicados por Lima [12], especificamente, 1, 2, 7, 14 e 28 dias com a lente de 10x. Após a imersão das lentes de contato quantum I nas soluções mencionadas sob condição estática e, em seguida sob perspectiva de cada tempo, as mesmas foram retiradas, secas em dessecador e levadas para análise de topografia com o objetivo inicial de avaliar o efeito das diferentes soluções sobre a superfície das lentes RGP (rígida gás permeável) indicadas para a patologia ceratocone, como ilustrado na figura 1.

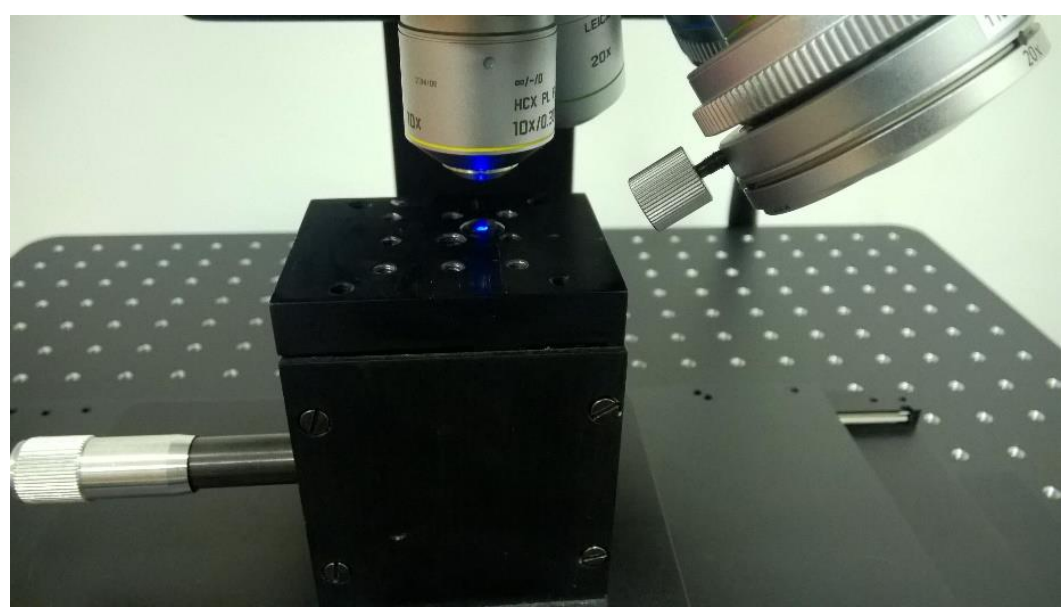

Figura 1. Detalhe do microscópio confocal LEICA DCM3D, com uma de lente de contato em análise topográfica.

As medidas de transmitância foram realizadas com o uso de um dispositivo objetivo por meio de uma impressora 3D especialmente projetado para esse fim (vide figura 2), a fim de usarmos o modo fotométrico do elipsômetro. Nas medidas de transmitância, mede-se em primeiro lugar o sinal de referência e depois o que atravessa o centro da lente. A razão entre eles é transmitância. Analisamos a variação 
temporal da mesma ao longo do experimento da superfície foram realizadas próximas ao centro da lente.

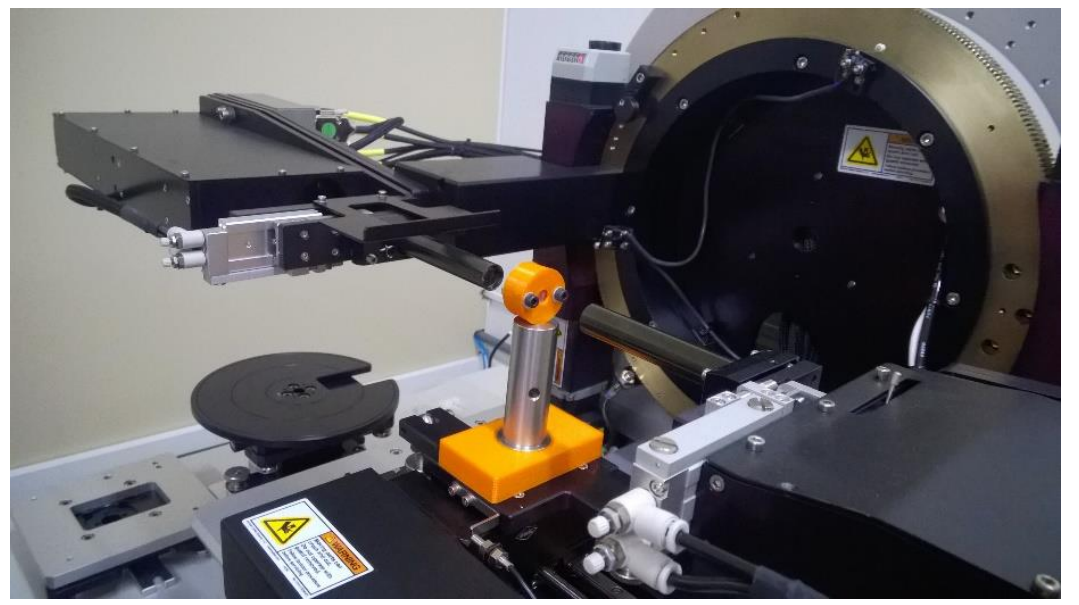

Figura 2. Análise de transmitância de lente contato, dentro do suporte especialmente projetado para este fim, e feito por impressão 3D para uso com o poste metálico, usando o modo fotométrico do elipsômetro SEMILAB GES 5S. Destacam-se os tubos metálicos, que contém as lentes colimadores (microspots).

\section{RESULTADOS E DISCUSSÃO}

Apresentaremos alguns dos resultados preliminares mais relevantes de nossa pesquisa. A imagem presente na Figura 3 representa a topografia da lente 1 (lente RGP- amostra controle) no dia 0, sem efeito de solução alguma. Percebe-se uma superfície regular, livre de riscos, sem elevações, deposições, depressões ou manchas, etc. Esse é um resultado típico para todas as lentes no dia 0.

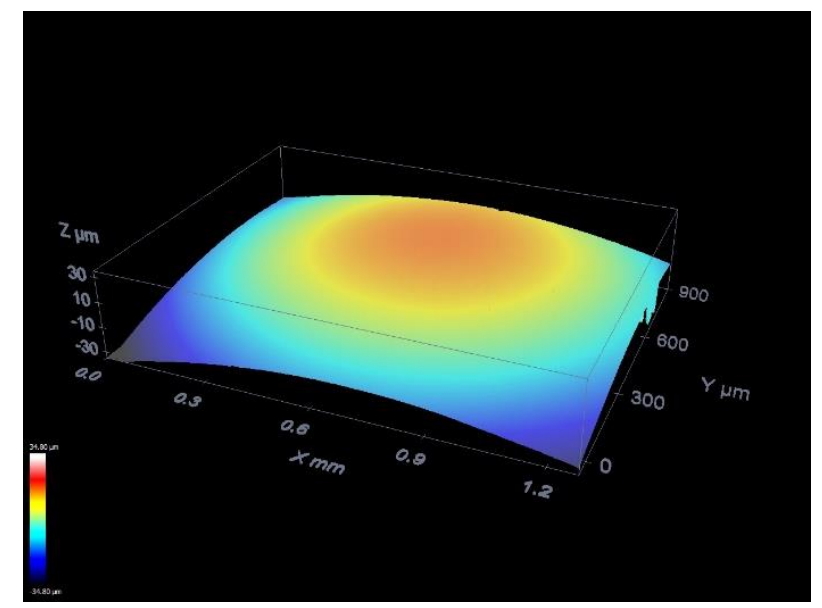

Figura 3. Imagem com informação topográfica da superfície da lente 1 no dia zero.

A figura 4 apresenta a lente 2 no dia 28, após a submissão à solução extrema de acetato de potássio $5 \%$ pH 5 . É notória a presença de marcas, manchas, etc., efeito da degradação. Pode-se comparar essa imagem com a da lente 1 submetida à solução multiação Boston Simplus indicada pelo fabricante, como ilustrado na Figura 5. É interessante perceber que mesmo usando a solução indicada pelo fabricante, a lente apresenta danos profundos após 28 dias [13]. 


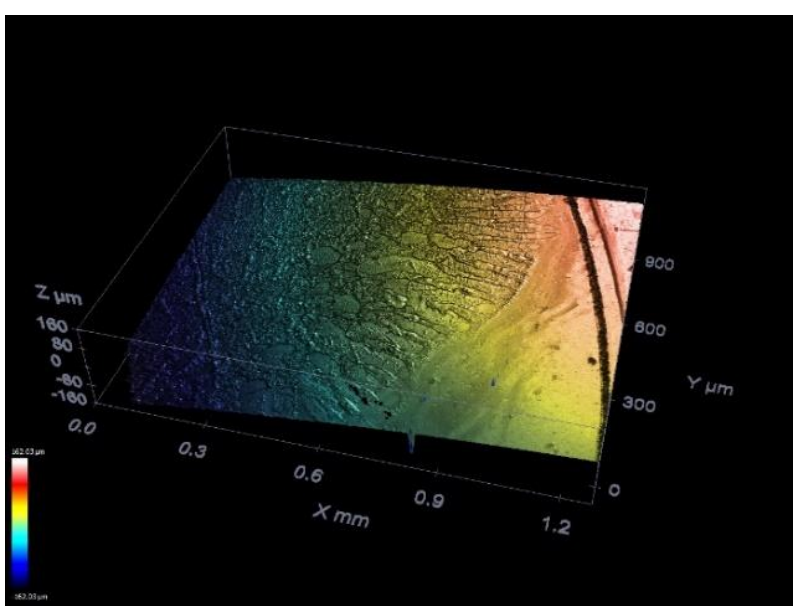

Figura 4. Imagem com informação topográfica da superfície da lente 2 no dia 28.

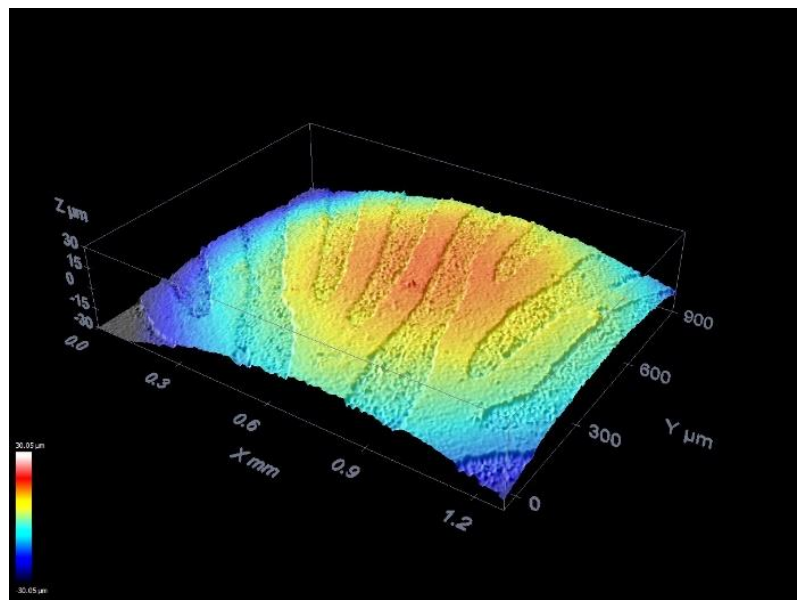

Figura 5. Imagem com informação topográfica da superfície da lente 1 no dia 28.

Outra análise interessante é da mudança das propriedades ópticas, nesse caso a transmitância. A transmitância da lente 1 no dia 0 é exibida na Figura 6. Percebe-se uma transmitância entre $73 \%$ e $83 \%$, na faixa do espectro visível (400 a $700 \mathrm{~nm}$ ). É possível perceber que os valores estão abaixo do esperado para o espectro visível de lentes que não tiveram contato com nenhuma solução [14-17].

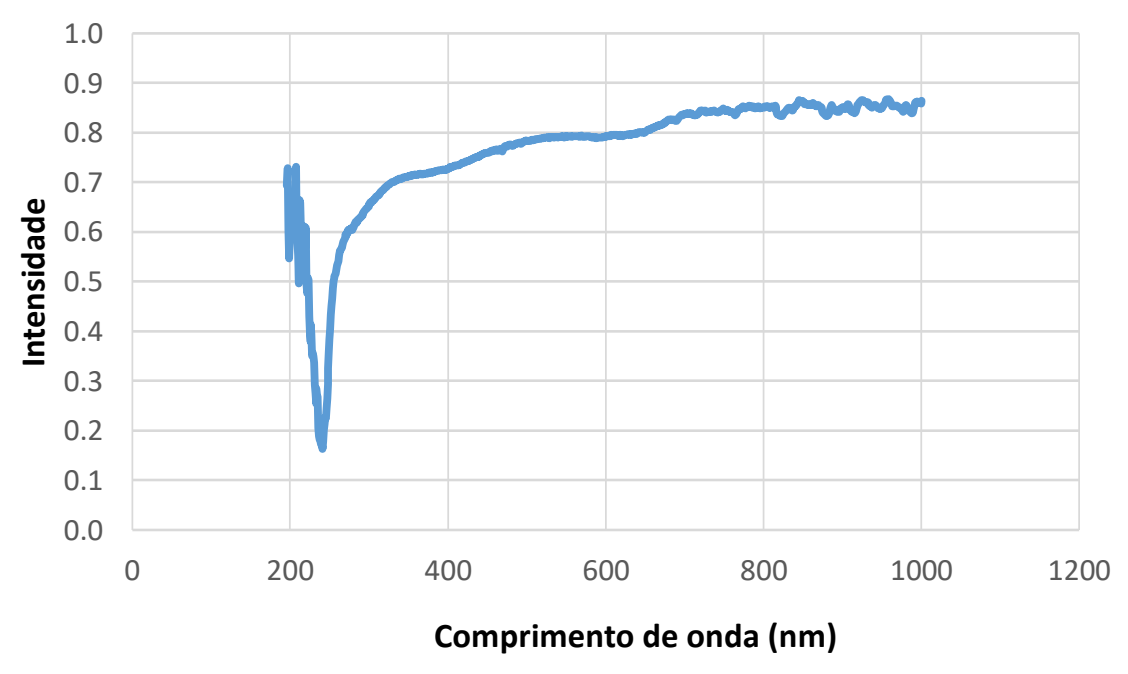

Figura 6. Transmitância da lente da lente 1 no dia zero. 
A figura 7 mostra a transmitância no dia 28 da lente 1. Percebe-se a variação no valor da transmitância após o período de aproximadamente 1 mês. Ela agora se situa entre $55 \%$ e $77 \%$ na faixa do visível. Essa queda acompanha as mudanças, ou seja, degradação, na topografia da lente. Entretanto o valor da transmitância sugere que a queda na transmitância não é tão grave quanto aparentam os danos na superfície. $\mathrm{A}$ possível continuidade de uso da lente pode acarretar riscos e maiores danos no contato com o olho, uma vez que os danos na superfície sugerem maior possibilidade de presença de bactérias.

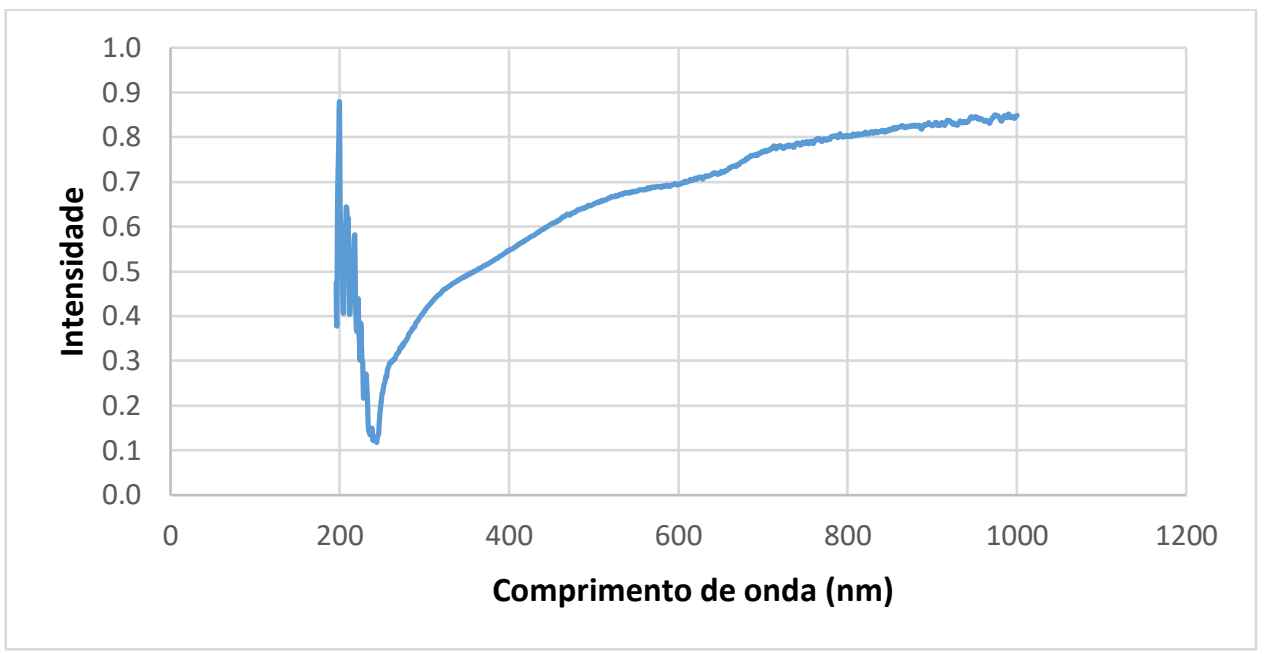

Figura 7. Transmitância da lente da lente 1 no dia 28.

A figura 8 ilustra o efeito para a lente 2 , no $14^{\circ}$ dia tratada com a solução extrema de acetato de potássio $5 \%$. A transmitância se situa entre $62 \%$ e $79 \%$. Essa lente se rompeu antes do $28{ }^{\circ}$ dia. De qualquer forma já se vê uma grande queda da transmitância entre o dia 0 e o dia 28.

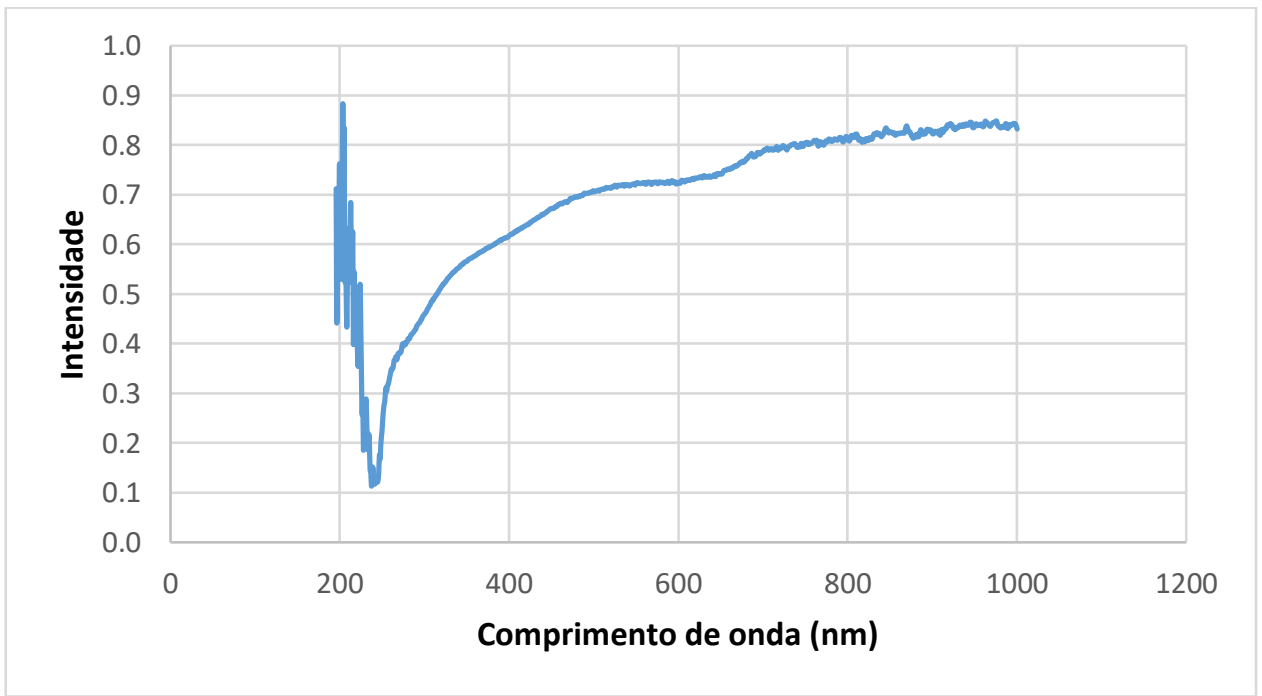

Figura 8. Transmitância da lente da lente 2 no dia 14.

A figura 9 exibe a transmitância para a lente 3 , tratada com em água ultrapura, no dia 28. Vê-se a grande queda da transmitância, uma vez que a mesma se encontra em $11 \%$ e $20 \%$. Uma queda vigorosa quando comparada com a solução do fabricante. 


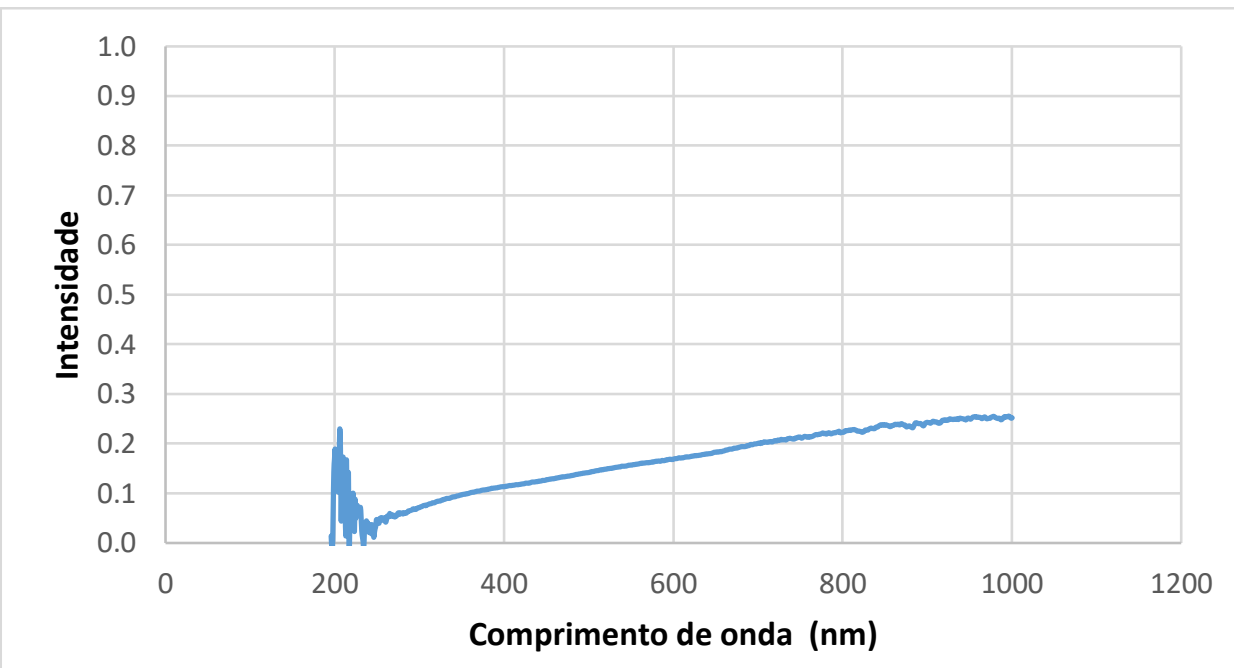

Figura 9. Transmitância da lente da lente 3 no dia 28.

Em relação aos valores de transmitância a lente 2 se destaca por manter a regularidade nos valores de sua transmitância desde a primeira medida até o dia 14, a transmitância do dia 28 não é mostrada devido ao rompimento da lente. A lente 3 possui a menor transmitância desde sua primeira medida, mas devido a dilatação de sua estrutura e perda de sua regularidade é possível inferir através das imagens 0 motivo de sua baixa transmitância ( $25 \%$ ) ao término do experimento. A lente 1 , imersa na solução proposta pelo fabricante (Boston Simplus) também apresenta regularidade nos valores de transmitância, e é possível identificar que o seu decréscimo ao longo do tempo é pequeno. Os valores de transmitância também são influenciados pela composição da lente [14], tempo de uso e solução na qual está imersa e o fator composição [14] é um importante indicador dos valores de transmitância. Destaca-se ainda, que o nosso estudo de degradação das lentes foi realizado sob condição estática, entretanto há outras metodologias [18-19] também aplicáveis a biomateriais.

\section{CONCLUSÃo}

Neste trabalho estudou-se a degradação da superfície de lentes de contato RGP relacionado ao efeito dos três meios usados por meio de análises via métodos ópticos, além de analisar características superficiais e ópticas. Avaliou-se a variação temporal da topografia e transmitância das superfícies das lentes. A análise topográfica foi capaz de detectar a grande deterioração de suas superfícies do dia inicial até o dia final. A lente 1 apresentou a menor degradação, quando avaliamos a topografia em conjunto com a transmitância. Sua transmitância pouco variou, permanecendo com valores próximos ao inicial. A lente 2 se rompeu antes do término do experimento, mas ainda assim apresentou grande degradação no 14 dia. A lente 3 apresentou a maior variação de transmitância, devido a dilatação de sua estrutura por presença de água ultrapura. Destaca-se a deterioração detectada pela topografia da superfície das lentes nos ensaios, mesmo na solução do fabricante - lente 1, e a queda não tão grande da transmitância. Isso sugere que é possível o uso prolongado da lente 1 (transmitância maior que $50 \%$ no dia 28), ainda que a topografia da superfície apresente riscos e alterações significativas. A próxima etapa do estudo se concentrará na análise da rugosidade superficial das lentes.

\section{Agradecimentos}


Agradecemos à FINEP pela aquisição do Elipsômetro e do Microscópio Confocal, à PROPPI-UFF pelo projeto FOPIN 2015, e ao M. Sc. Jorge Nicolau pelo projeto e confecção dos suportes para lentes de contato.

\section{REFERÊNCIAS}

1 Giraldez MJ, et al. Contact Lens Hydrophobicity and Roughness Effects on Bacterial Adhesion. Optometry and Vision Science. 2010;87(6): E426-E431.

2 Das S. Contact lens fitting in keratoconus - a prospective study on visual and functional outcomes. Int. J. Res. Med. Sci. 2015;3(8):1851-1857.

3 Coral-Ghanem C, et al. Lentes de contato terapêuticas e as vantagens dos materiais de alto Dk. Arq. Bras. Oftalmol. 2008;71(6 Supl):19-22.

4 Ferreiro AVS, et al. Evolución histórica de las lentes de contacto. Servicio de Oftalmología, Sociedad Española de Oftalmologia. 2012;87(8):263-266.

5 Mogollón JFP, Lobão-Neto AA. Una Breve Historia \& Evolución de las Lentes de Contacto Blandos - Parte 1: Materiales. Revista Pan-Americana de Lentes de Contato. 2009;1(1):5-8.

6 Elias PMS, Uras CLR, Pavês L. Ceratocone: fatores prognósticos. Arq. Bras. Oftalmol. 2005;68(4):491-4.

7 Mannis MJ, Zadnik K, Coral-Ghanem C, Kara-José N. Contact Lenses in Ophthalmic Practice. New York: Springer-Verlag, 2004.

8 Matsuhara ML, et al. Espectrofotometria de lentes oftálmicas orgânicas de visão simples submetidas à radiação ultravioleta $A$, ultravioleta $B$ e luz visível. Arq. Bras. Oftalmol. 2004;67(4):571-4.

9 Robert HW. Confocal optical microscopy. Rep. Prog. Phys. 1996;59: 427-471.

10 Pereira I. Estudo da degradação de compósitos reforçados com fibras biodegradáveis para aplicações biomédicas. Dissertação de Mestrado em Engenharia Biomédica, FEUP, 2010.

11 Kreling A. Estudo do efeito da espessura e da temperatura de recozimento nas propriedades ópticas e morfológicas de filmes finos de nitreto de silício. Dissertação de Mestrado. Universidade Federal Fluminense, Volta Redonda-RJ, 2015.

12 Lima IR, et al. Produção, caracterização físico-química e degradação estática e dinâmica in vitro de grânulos de $\beta-$ TCP. Painel PEMM/COPPE/UFRJ. Rio de Janeiro, 2011.

13 Lira $M$, et al. Surface roughness and refractive index changes in contact lens induced by lens care systems. Eye \& Contact Lens. 2014;40(3):140-147.

14 Rahman S, et al. Spectral transmittance of UV-blocking soft contact lenses: A comparative study. Contact Lenses \& Anterior Eye. 2014;37: 451-454.

15 Lin KK, Lin YC, Lee JS, Chao AN, Henry SLC. Spectral transmission characteristics of spectacle, contact, and intraocular lenses. Ann. Ophthalmol. 2002;34(3):206-125.

16 Moore L, Ferreira JT. Ultraviolet (UV) transmittance characteristics of daily disposable and silicone hydrogel contact lenses. Contact Lens Anterior Eye. 2006;29: 115-122.

17 Abadi RV, Davies IP, Papas E. The spectral transmittance of hydrogel contact lens filters. Ophthalmic. Physiol. Opt.1989;9(4):360-367. 
18 Yildirimer L, Seifalian AM. Three-dimensional biomaterial degradation - Material choice, design and extrinsic factor considerations. Biotechnology Advances 2014;32: 984-999.

19 Zhang $\mathrm{X}$, et al. Polymer-polymer composites for the design of strong and tough degradable biomaterials. Materials Today Communications. 2016;8: 53-63. 